\title{
Cenários prospectivos das organizações de mídia impressa e hori- zontes para a carreira de jornalista: tensões, responsabilidades e mutações estruturais
}

\author{
Prospective scenarios of print media organizations and horizons for \\ career journalist: tensions, responsibilities and structural changes
}

http://dx.doi.org/10.5007/2178-4582.2014v48n1p124

Felipe Arruda Mortara

Pontifíicia Universidade Católica de São Paulo, São Paulo/SP, Brasil

Leonardo Nelmi Trevisan

Pontifícia Universidade Católica de São Paulo e Escola Superior de Propaganda e Marketing, São Paulo/SP, Brasil

Este artigo visa compreender, por meio da teoria de cenários, as atribuições e responsabilidades que farão parte do cotidiano de trabalho do profissional de jornalismo impresso no Brasil e os contextos de estrutura organizacional e demanda por conteúdo em que possivelmente exercerá sua atividade dentro de cinco anos. Com base nas principais teorias de carreira e suas alternativas, construiu-se um ensaio teórico sobre as tensões que marcam a relação entre jornalistas e empresas de mídia. A compreensão do histórico destas relações, bem como o das relações de consumo como cultura social, somada a um entendimento do contexto em que vivemos, permite reunir elementos e hipóteses que sinalizam por quais caminhos seguem a demanda e a oferta de informação. Paralelamente, apresenta um panorama das transformações na carreira do jornalista. A partir desses indicativos, foram construídos possíveis cenários de tarefas e ambientes em que os profissionais do jornalismo atuarão.

Palavras-chave: jornalismo; carreira; mercado; trabalho; comunicação
This article aims to understand, through the theory of scenarios, the duties and responsibilities that will take part of the daily work of print journalism professionals in Brazil and the contexts of organizational structure and demand for content that they will possibly face within five years. Based on the main theories of career and their alternatives, we have built a theoretical essay on the tensions that marked the relationship between journalists and media companies. Comprehending the history of these relations, as well as the consumer relations as social culture, coupled with an understanding of the context in which we live, allow us gather elements and hypotheses that signal the paths in which the demand and supply of information will follow. In parallel, it provides an overview of changes in the journalists career. From these indications, we built three scenarios of tasks and environments in which professional journalists will probably act.

Keywords: Journalism - Career - Market - Work Communication

\section{Introdução}

Com o advento da internet e de outras tecnologias que possibilitaram o acesso mais veloz à informação, questiona-se cada vez mais a importância, os modos de fazer, a relevância e os custos de um jornal diário impresso. Sem dúvida, a imprensa escrita vive tempos incertos e tem sua existência ou per- 
manência frequentemente questionada. Numa era de informação abundante, em que as redes sociais ocupam um espaço não antes previsto, e na qual muita informação tem sido oferecida gratuitamente e a granel, é impossível pensar no futuro da informação de qualidade sem pensar na carreira dos profissionais responsáveis por apurá-la, filtrá-la e disseminá-la: os jornalistas.

Acrescente-se a relevância de pensar o jornalista em uma abordagem de carreiras sem fronteiras (ARTHUR; ROUSSEAU, 1996), na qual este profissional deve saber aprender, ser adaptável e flexível às novas transformações do mercado e às novas oportunidades de trabalho que possam surgir. Como elenca Veloso (2010), esta teoria considera que a carreira se move através de fronteiras de empregadores distintos, como por exemplo os especialistas em alta tecnologia no Vale do Silício; ou quando a carreira possibilita a comercialização do trabalho de forma autônoma ou complementar, como o profissional que também atua como professor. Também se configura quando uma carreira é sustentada por networks ou informações externas (por exemplo, corretor de imóveis ou de bolsa de valores), quando a pessoa rejeita oportunidades de carreira por motivos pessoais ou familiares ou, ainda, quando se quebram discursos hierárquicos e progressos para ampliar a rede de relacionamentos (ARTHUR; INKSON; PRINGLE, 1999).

Considerando a turbulência que atinge os ambientes de trabalho na nova economia, que diminuiu a segurança em todos os níveis hierárquicos e sociais, Hall (2002) afirma que o contrato tradicional de carreira, com promessas de estabilidade e emprego de longo prazo, é substituído por contratos de curto prazo, renovados semanal ou mensalmente, com base em desempenho e em necessidades correntes. Portanto, faz-se necessário também que consideremos a abordagem de carreira proteana (HALL, 1996), especialmente suas principais premissas: mudanças frequentes, autoinvenção, autonomia, autodireção, habilidade para aprender, habilidade para redirecionar a carreira e a vida, e habilidade para construir relações. A carreira é gerida pela própria pessoa e não pela organização. As necessidades pessoais e o sucesso psicológico, oposto ao sucesso exterior, é o que impulsiona este tipo de carreira. O que compõe esta ideia de carreira é uma sucessão de experiências ao longo da vida: qualificações, aprendizados, transições e mudanças de identidade. Este novo contrato de carreira requer que a pessoa aprenda o que e como aprender, e também a aprender continuamente sobre os outros e sobre si própria. A identidade é vista como uma metacompetência, "a capacitação de alta ordem que habilita a pessoa a adquirir novas habilidades" (VELOSO: DUTRA, 2010).

Por outro lado, o tema justifica-se socialmente, uma vez que os jornais observam suas vendas e circulação caírem (MEIO E MENSAGEM, 2014; JACKSON, 2013) e, por consequência, seu prestígio e abrangência públicos. Além disso, têm sua eficácia como meio de comunicação sendo questionada por anunciantes, que cada vez mais optam por estratégias publicitárias onli$n e$, por meio de redes sociais e outros canais. Esta situação é provocada pelo desinteresse cada vez maior por parte de um público leitor - em especial os 
jovens - que, desde cedo, foi introduzido às plataformas digitais e faz delas sua principal fonte de informação (LINS DA SILVA, 2009). Embora os dados brasileiros de vendas oficiais sejam inacessíveis, é notório que as vendas caíram consideravelmente - por ilação. Reportagem publicada no jornal $O$ Estado de S. Paulo aponta que há um projeto de lei que autoriza bancas de jornal a comercializarem produtos alimentícios, tornando-se minimercados, uma vez que as vendas de informação impressa já não lhes garante o rendimento.

\begin{abstract}
[...] Na justificativa do projeto de lei, José Américo dizia que as bancas de jornal sofrem com queda no faturamento nos últimos anos. "Não há justificativa razoável para que o poder público continue negando a ampliação no rol dos produtos que as bancas podem vender", diz o texto. O vereador argumenta que há uma concorrência desleal com as lojas de conveniência, que vendem alimentos, bebidas, jornais e revistas (DANTAS, 2013).
\end{abstract}

A convergência tecnológica (JENKINS, 2008) constitui fato iminente e representa a transição em curso na maneira de se informar. No entanto, esta transformação impacta diretamente a forma como se relacionam empresários de comunicação e jornalistas e, principalmente, a forma como o jornalismo é feito. As tarefas já não são as mesmas; ao jornalista não basta apenas escrever, ele deve filmar, editar, gravar, entrar ao vivo em rádios, fotografar com a câmera do smartphone, e rapidamente atualizar portais de internet.

Com mudanças tão consideráveis, e frente à incompreensão sobre as direções a serem tomadas, tanto pelas organizações como pelos profissionais que nela trabalham, é pertinente traçar possíveis cenários para os próximos anos, tanto para as empresas como para jornalistas que já atuam no mercado. Tratase de interpretar os sinais das recentes e constantes transformações para traçar possíveis horizontes neste campo.

Consideremos que tanto os grupos editoriais responsáveis por jornais e revistas como os próprios jornalistas parecem ainda não ter aprendido a ler e interpretar o horizonte atual. Para Arthur Sulzberger, editor do New York Times, "A crise do setor é dura, tem requerido grande capacidade de adaptação numa transição tecnológica que cobra novas soluções a todo momento" (GREENHALGH, 2012). Portanto, vivemos em um ambiente de mudanças constantes onde cabe questionar quais os potenciais caminhos a serem seguidos e imaginar, ou melhor, construir, possíveis cenários (HEIJDEN, 2009) e, com base em sua plausibilidade e não em sua probabilidade, tomar eventuais decisões.

O objetivo deste artigo é realizar um exercício de combinação e análise de possibilidades considerando sequências de eventos em contextos cabíveis. Assim, reuniremos ao fim do artigo três cenários plausíveis que possam ser respostas aceitáveis e pertinentes à seguinte questão: dentro de cinco anos, quais serão as funções do jornalista que hoje atua na mídia impressa? 


\section{Evolução: as transformações nas organizações de comunicação e o impacto na carreira dos jornalistas}

Sempre que uma nova tecnologia surge e se consolida, vem acompanhada da pergunta: o que será das antecessoras? Com o jornalismo não é diferente. $\mathrm{O}$ mercado dos grandes grupos de comunicação foi, ao longo da história, adaptando-se ao surgimento de novas plataformas de transmissão de informação, fruto de evolução tecnológica pura e simples, mas também de transformações nos contextos econômico-sociais. Cada vez que um novo meio prospera, especula-se sobre o fim dos veículos então tradicionais até mesmo como um sinal de progresso de evolução, seguindo o culto ao novo (BRIGGS; BURKE, 2005).

No início do século XX, a principal força do jornalismo, talvez por ser a única até então, era o impresso. Reinou forte até os anos 1930 quando o rádio se firmou como um meio ágil e que trouxe o considerável advento de transmitir ao vivo: podia-se acompanhar a notícia - ou pelo menos o seu relato - em tempo real. A novidade não era apenas o novo aparelho, que começava a entrar nos domicílios brasileiros, mas uma nova relação com a informação, com os comunicadores, com o mundo. Ao mesmo tempo em que a tecnologia aproximou o mundo, e todas as suas possibilidades, das pessoas, também forçou as organizações a encontrarem um novo modelo de negócio. No entanto, os jornais continuaram existindo, produzindo conteúdo, investigando e pautando os principais assuntos em discussão, e atendendo a um público-alvo que, apesar de estar diminuindo nos últimos anos, ainda os buscam como fontes respeitadas de informação com credibilidade (BIANCO, 2010).

Com o surgimento da televisão não foi diferente. Pelo valor alto da nova tecnologia, aos poucos, o acesso foi passando dos lares mais abastados para camadas mais populares da população. Muito se especulou sobre o fim do rádio como ferramenta eficaz, mas o que se vê, mais de 60 após a introdução dos televisores no Brasil, é que o rádio - e a indústria que gira em torno dele - não apenas não se extinguiu como encontrou um nicho de mercado para perpetuarse (NEUBERGER, 2012). Um bom exemplo é que, com o aumento da venda de veículos, especialmente nas grandes cidades, as pessoas passam mais tempo no trânsito e, para estas, o rádio oferece exatamente o tipo de informação que precisam (BIANCO, 2010).

Nos últimos 20 anos a utilização dos computadores pessoais, tanto no ambiente residencial quanto no de trabalho, multiplicou-se exponencialmente e, com eles, o uso da internet. A rede mundial de computadores pode ser definida, sem exageros, como a mudança crucial para os veículos de comunicação que surgiram antes. E, assim como estes, a internet continua se aprimorando e ganhando um papel de destaque e em contínua mutação.

Como aparelhos móveis possuem câmeras com resolução e recursos cada vez mais sofisticados (como zoom, edição, filtros) e com acesso à rede por wi$f i$ ou $3 \mathrm{G}$, vídeos e fotos são commodities produzidas a granel e compartilhadas 
nas redes sociais, como Facebook, Twitter e Instagram. Chegamos, como antecipado por Jenkins (2008), a um ponto crítico: a convergência tecnológica. Com todos os meios interligados e, ao mesmo tempo, com o consumidor podendo tornar-se também produtor de conteúdos, as relações de consumo e oferta de informação transformam-se drasticamente. A situação atual implica uma participação muito mais ativa e direta dos consumidores, obrigando as grandes indústrias a mudarem suas estratégias numa direção que converge para as necessidades atuais dos indivíduos. A convergência surge, assim, através do fluir de conteúdos por várias plataformas. O processo de convergência é complexo e em constante mutação, uma vez que é dependente da relação entre tecnologia e cultura.

\section{As transformações na carreira do jornalista}

Os profissionais da comunicação que trabalham no Brasil enfrentam questionamentos que vão além da própria prática comunicativa (LIMA; FIGARO, 2010). Por pertencerem a uma engrenagem que busca simultaneamente informar e gerar dividendos, estes profissionais também se encontram numa encruzilhada que diz respeito à própria carreira, à realidade do mercado e às convicções e valores pelos quais se orientaram .

Com a necessidade de reduzir custos, e empurradas pela pressão das novas tecnologias, muitas empresas de comunicação passaram a enxugar suas redações e a concentrar tarefas em uma equipe reduzida. Devido a isso, nos últimos anos, temos visto, em portais, revistas e até em veículos impressos, profissionais que são - ao mesmo tempo - responsáveis por escrever, filmar, fotografar, editar e subir notícias, fazer coberturas de eventos online e ao vivo. Enfim, tarefas não faltam, e este novo profissional multimídia, obviamente, não acumula os salários de seus antigos colegas (LARA, s/d.). Em breve não se saberá mais o que é uma função e outra, tamanha a unificação dos meios (JENKINS, 2008) e, ao jornalista, será dado apenas o conjunto de tarefas a executar, sem distinção, o que aumenta os temores e utilidade de uma qualificação adequada, e até mesmo um projeto de carreira.

Não obstante, se olharmos para outras carreiras, como a de advogados ou de engenheiros, observamos relações e oscilações igualmente instáveis e transformadoras. Os engenheiros viveram um auge de demanda nos anos 1970, por conta do contexto de grandes obras pelo Brasil, como usinas hidrelétricas, estradas e shoppings centers. Nas duas décadas seguintes, com o aumento da inflação, o setor da construção civil e o mercado imobiliário tiveram menos investimentos, entrando em recessão. Assim, muitos engenheiros migraram para outros setores, especialmente o mercado financeiro. Depois, com o aumento da tecnologia nos canteiros de obra, as obras passaram a contar com um alto nível de industrialização, porém, passou-se a demandar dos engenheiros ainda mais qualificação e conhecimento de negócios, além de bagagem técnica (NEVES, 2012). 
De outro lado, na comunicação, pode-se supor que temos um padrão de vínculos curtos, jornadas intensas e baixos salários? Se sim, cabe entender as razões, tanto do lado do profissional que oferece sua mão de obra, quanto do empregador. Um possível motivo para essa ausência de consideração verdadeira e remuneração justa perante às capacidades dos jornalistas pode ser simplesmente o número de 12 mil novos recém-formados nos 317 de cursos de graduação no país (MICK; LIMA, 2013), ávidos para entrar no mercado e, como se diz popularmente, "mostrar serviço".

Carreira é um termo que permite uma quantidade excessiva de significados (HALL, 2002), com conotações distintas usadas tanto popular quanto academicamente. A visão mais comum é a de carreira como avanço, com mobilidade vertical em uma hierarquia organizacional com sequência de promoções e movimentos para cima. Para London e Stumph (1982), carreira consiste na sequência de posições ocupadas e de trabalhos realizados durante a vida professional de uma pessoa, considerando que o entendimento e a avaliação das experiências profissionais fazem parte da perspectiva do individuo na carreira. Portanto, a carreira envolve a ocorrência de transições ligadas a necessidades individuais e imposições da organização e da sociedade. Hall (2002, p.44) resume as várias concepções reunidas em seu estudo e define carreira como "a sequência individualmente percebida de atitudes e comportamentos associada com experiências relacionadas ao trabalho e atividades durante a vida de uma pessoa".

A fim de se estabelecer uma compreensão da evolução das diversas teorias de carreiras, retraçaremos uma breve retrospectiva. No início dos anos 1970 ainda não existia um campo estabelecido para análise do estudo de carreira nas organizações para formar uma teoria capaz de ser aplicada em amplas pesquisas (ARTHUR; HALL; LAWRENCE, 1989). À época, a principal base teórica era oriunda dos campos da psicologia vocacional e da sociologia. Porém, na metade daquela década surgiram três obras-chave para aprofundar e ampliar o estudo de carreiras: Career in Organizations (HALL, 1976); Organizational careers (VAN MAANER, 1977); e Career Dynamics (SCHEIN, 1978).

A partir dos anos 1980, aumentou o interesse pelo tema, com mais grupos, eventos e obras discutindo carreiras. O desenvolvimento da teoria, pesquisa e prática tinha atenção voltada ao planejamento de recursos humanos. As principais pesquisas abordavam planos de avaliação e sucessão, desenvolvimento do potencial de gerência, bem como aprimoramento das competências dos gerentes por meio de coaching e counselling. Foram sucedidas por movimentos não tradicionais, que abordavam o desenvolvimento profissional de minorias e mulheres. O principal resultado literário deste período foi o Handbook of career theory (ARTHUR; HALL; LAWRENCE, 1989), que consolidou a proposta de sistematiza a carreira.

A partir das décadas seguintes consolidaram-se o que chamamos de visões tradicionais de carreiras, além de uma série de outras abordagens alternativas. 
Nesta época, ganharam força abordagens que não consideravam mais expectativas profissionais de longo prazo dentro de uma única organização, como evidenciando que os recursos haviam se tornado mais escassos e que as culturas organizacionais e sociais haviam mudado. Uma destas abordagens, a da carreira proteana (HALL, 1996), indica um maior foco em significado do que em dinheiro, em propósito do que em poder, em identidade do que em ego, em aprendizado do que em talento.

Outra contribuição considerável deste período para o estudo de carreiras foi a ideia de carreira sem fronteira, que apesar de não configurar uma forma singular de carreira, abrange possíveis formas e desafia as concepções tradicionais de trabalho. The boundaryless career, uma compilação de textos sobre novas tendências do trabalho (ARTHUR; ROUSSEAU, 1996) surge mais como obra questionadora e desafiadora dos padrões e ideias vigentes do que propriamente uma teoria objetiva, concreta. No Brasil, Administração de carreiras (DUTRA, 1996), a primeira obra dedicada especificamente ao tema, surge no mesmo ano, destinada a profissionais interessados em gestão de pessoas, estudantes da área e trabalhadores comuns interessados em pensar ou repensar suas trajetórias.

Ainda nos anos 1990, destaque para a ideia das âncoras de carreira (SCHEIN, 1996), que interpreta como os elementos da personalidade, realidade e da história da pessoa indicam padrões de escolha em sua trajetória profissional. O conceito foi elaborado a partir de uma densa pesquisa da Sloan School of Management do Massachusetts Institute of Technology (MIT), que entre 1961 e 1973 acompanhou e analisou os perfis e comportamento de 44 alunos ao longo de suas carreiras. Descreveu-se um conjunto de valores, necessidades, atitudes autopercebidas e talentos, que podem ser desenvolvidos com o tempo e construir guias e direções. Estas referências poderiam servir como embasamento para decidir sobre mudanças de trabalho e escolhas de grande importância dentro do universo profissional.

\section{Construção de cenários}

Como vimos, são inúmeros os fatores que compõem o universo da prática contemporânea do jornalismo impresso no Brasil, e sua evolução até este ponto foi decorrente de relações complexas não apenas entre as organizações de comunicação e seus profissionais, mas também entre a imprensa e a sociedade. Considerando o que se espera dos veículos de imprensa, as constantes transformações nas maneiras de transmitir informação, das novas tecnologias e da forma como o público em geral se relaciona com notícias, faremos em seguida um exercício de construção de cenários (HEIJDEN, 2009). Para tanto, levaremos em conta igualmente o retrospecto da situação das organizações de mídia, assim como as teorias de carreira sem fronteira (ARTHUR; ROUSSEAU, 1996) e proteana (HALL, 1996). Por motivos de espaço, não se 
pretende traçar panoramas aprofundados, senão nortear possíveis contextos, com reações causais entre fatos, numa reflexão dedutiva. Muito importante: consideraremos a plausibilidade, o fator causal, e não a probabilidade dos fatos, ou seja, a questão da frequência. Partamos, portanto, para a reflexão sobre a questão: dentro de cinco anos, quais serão as funções do jornalista que hoje atua em redações de mídia impressa?

\section{Cenário 1. Adaptação parcial e relações profissionais conflituosas}

Ainda muito vinculadas à sua atividade de mídia impressa, as organizações continuariam apostando parcialmente nas mídias digitais, sem realizar por completo a transição, de forma a se tornarem cada vez mais sem identidade. Desta maneira, ainda procurariam apoiar-se na solidez e tradição de suas marcas como veículos de comunicação, a fim de garantir a solidez de seus resultados. Estes atributos seriam as forças motrizes (HEIJDEN, 2009) deste cenário, ou seja, os "guardadores de lugar" de uma força ambiental que pode estar causando uma consequência onde existe uma incerteza crítica. Esta última, por sua vez, rotula uma dimensão da situação que emerge de um processo de priorização como sendo mais importante e mais incerto.

A principal fonte de renda dessas organizações ainda seria proveniente dos anúncios impressos, sendo relegada à publicidade digital a pecha de 'menos rentável e menos importante', sem criar condições de transformar este quadro, uma vez que ainda não se acreditaria - de fato - numa mudança do analógico para o digital, apesar de ainda manterem um site atualizado e, pretensamente, valorizarem a velocidade da internet.

Através de uma estruturação dedutiva de cenários - isto é, de um raciocínio pelo qual uma conclusão específica deriva, lógica e necessariamente, de um conjunto de premissas gerais (HEIJDEN, 2009) - chegaríamos a uma série de outras constatações, como o acúmulo cada vez maior de funções por parte do jornalista. Não apenas seriam responsáveis, como já são, por apurar informação, fotografar, filmar, atualizar redes sociais, gravar comentários para rádios, como teriam de editar esses conteúdos e, ainda, exercer interpretações complexas a cerca dos fatos. Desta forma, as redações seriam ainda mais enxutas, e os cadernos menores em tamanho. Do jornalista seria cobrada a tarefa de um analista, de um comentarista com atribuições de avaliar panoramas, traçar paralelos e fazer leituras diferenciadas.

A teoria das carreiras sem fronteiras (ARTHUR, 1994) se aplicaria aos jornalistas que optassem por se adaptar a este contexto, levando em conta fatores de flexibilidade e de independência entre a pessoa e a empresa. O profissional deveria saber aprender, ser adaptável e flexível às novas transformações do mercado e às novas oportunidades de trabalho que possam surgir. Sua carreira transcenderia as fronteiras de uma única organização e ele deveria, continuamente, dirigir sua própria carreira, o que pode ser facilitado por meio de uma maior rede de relacionamentos. Muitos dos que não se encaixassem 
nesta lógica partiriam para outras formas de praticar o jornalismo, seja com trabalhos "free-lance", ou abrindo seus próprios projetos, como blogs ou revistas segmentados.

\section{Cenário 2. Adaptação mútua com sucesso e harmonia}

Sempre considerando o papel da imprensa de informar e a função do jornalista em constante transição, neste cenário, organizações e profissionais encontrariam um ponto de equilíbrio. Para tanto, as empresas não apenas reconheceriam que devem, como de fato perseguiriam, permanentemente, as mais contemporâneas formas de transmitir informação, bem como aceitariam desprender-se - ou ao menos repensar - as antigas formas. Desta maneira, estariam colocando em prática uma transformação de fato, impondo ao mercado sua importância como prestigiosos veículos comunicadores e alterando a forma de faturar com publicidade, que até cinco anos antes era majoritariamente embasada na mídia impressa. Pode-se dizer que, assim, abraçariam sua própria incerteza crítica (HEIJDEN, 2009), aproveitando-a como parte positiva do cenário, utilizando-a em benefício próprio. As mídias digitais deixariam de ser um apêndice do veículo impresso para tornarem-se prioridade, relegando o impresso ao segundo plano, porém sem eliminá-lo. O caminho para o segmento impresso seria a segmentação, com temas voltados a públicos mais específicos e tiragens menores.

\section{Cenário 3. Adaptação organizacional com instabilidades profissionais}

Neste cenário, as empresas de mídia impressa encontrariam, pouco a pouco, equilíbrio e sentido em suas atividades, assimilando melhor seus novos papéis de comunicadores e adaptando-se, com versatilidade, às novas mídias. Aos poucos, conseguiriam fazer a transição comercial e alterariam seu modelo de negócio, de maneira a faturarem mais com comunicação digital e menos com a impressa, relegando a esta um papel menor, ainda que reconhecessem sua importância até ali.

Entretanto, o que é mais provável é que, se a organização encontrasse um ponto de equilíbrio trabalhando assim, não abriria mão de aumentar a produtividade de seus funcionários ao extremo - reduzindo o número de profissionais e aumentando sua carga de trabalho e exigência de rendimento. Neste ponto, caberá ao jornalista aceitar esta nova situação, compreender quais são suas opções e organizar sua carreira de forma proteana (HALL, 1996), a fim de se adaptar a uma nova realidade de instabilidade e insegurança nas empresas, já que estas buscarão operar com um quadro cada vez mais enxuto de funcionários.

Com isso, o profissional deverá ter em mente suas primeiras premissas: mudanças frequentes, autoinvenção e autodireção. O que guia esse tipo de carreira são as necessidades pessoais e o sucesso psicológico, e é isso que o 
jornalista deve almejar. Para tanto, considera duas formas de contrato psicológico: relacional, com vínculo mútuo, de confiança e de longo prazo entre indivíduo e organização; e transacional, baseado em trocas utilitárias de benefícios e contribuições de curto prazo (HALL, 1996). Não será nada comum, como já ocorre hoje em coberturas especiais - como eleições, Copa do Mundo, Olimpíadas, - que se concentre o número de jornalistas nas redações por um período pré-determinado, a fim de executarem um projeto pontual, que geralmente conta com patrocínio e anunciantes específicos.

\section{Considerações finais}

Traçados os cenários nas páginas anteriores, é de suma importância que recapitulemos alguns eixos-chave, a fim de nortear possíveis desencadeamentos de contextos e fatos. Esteja o jornalista em qualquer uma das funções de uma redação, a sobrevivência exigirá dele cada vez mais uma postura autônoma, isto é, que seja um intraempreendedor (PINCHOT, 1989) dentro das organizações. Por empreendedor entenda-se um funcionário dinâmico, criativo, sem desrespeitar as tradições da empresa, que arrisque-se, mas sem colocar a organização em risco, e que seja proativo sem desrespeitar a hierarquia (TREVISAN, AMORIM, MORGADO, 2011). Postura e terminologia em linha com o que acontece na maior parte das empresas de qualquer mercado, busca-se líderes, ainda que não tenham equipes para liderar.

A carreira do jornalista tende a transcender as fronteiras de uma única organização, e ele deverá, continuamente, dirigir sua própria carreira, o que pode ser facilitado por meio de uma maior rede de relacionamentos. Devem ganhar força os aspectos de gestão individual e autocondução de sua carreira, tornando o jornalista um empreendedor de si mesmo. Acrescente-se que a necessidade de versatilidade e flexibilidade para se manter no mercado se impõe igualmente às organizações, o que deve leva-las a também procurar sua identidade como organizações sem fronteiras. Resta saber se as próprias organizações reunirão fôlego e disposição para se colocarem em mercados que as permitam experimentar e aprender continuamente, recombinando conhecimento local, qualificações e tecnologia.

A compreensão do histórico das relações anteriores entre jornalistas e empresários da comunicação (grandes grupos de mídia), juntamente com as relações de consumo como cultura social, somadas a um entendimento do contexto em que vivemos e das principais teorias de carreira, reúne elementos suficientes para pensarmos que um panorama das transformações na carreira do jornalista justifica a reflexão sobre possíveis cenários de tarefas e ambientes em que os profissionais do jornalismo atuarão.

Em um contexto de mudanças tecnológicas, em que empresas de comunicação e seus atores tentam redefinir a cada dia seu novo papel, buscamos entender como - e se -é possível que um profissional de comunicação estabeleça 
uma gestão coerente de sua própria carreira, com base nos modelos proteano (HALL, 1996) e sem fronteiras (ARTHUR; ROUSSEAU, 1996). Aqui faz-se um contraponto ao constante desejo de ser mais - desafiando e superando, sem trégua, os próprios limites - que cativa o imaginário contemporâneo, mobilizando energias psíquicas, anseios narcísicos de reconhecimento e fantasias de onipotência (FILHO, 2011).

Afim de nos aprofundarmos ainda mais nas questões levantadas neste artigo, cabe considerar a realização de novos estudos, que ramifiquem e agreguem novas informações, as reconfigurando. Podemos pensar numa futura pesquisa que analise em que medida o jornalista exerce sua atividade por paixão à profissão, quais os paradoxos de sua escolha ao perceber-se como parte de uma engrenagem da indústria cultural e não mais como ator social com ação política, idealizado muitas vezes quando da escolha da carreira e do curso superior, e os conflitos decorrentes dessa escolha com as âncoras de carreira (SCHEIN, 1996), majoritariamente presentes entre os jornalistas de mídia impressa.

\section{Referências}

ARTHUR, M. B. The Boundaryless carrer: a new perspective for organizational inquiry. Journal of Management Behaviour, [S.1.], v. 15, n. 15, p. 295-306, 1994.

ARTHUR, M. B; HALL, D. T.; LAWRENCE, B. S. Generating new directions in career theory: the case for a transdisciplinary approach. In: ARTHUR, M. B.; HALL, D. T.; LAWRENCE, B. S. (Ed.) Handbook of Career Theory. New York: Cambridge University Press, 1989, p. 131-147.

ARTHUR, M. B INKSON, K.; PRINGLE, J. K. The new careers: individual action and economic change. London: Sage Publications, 1999.

ARTHUR, M. B; ROUSSEAU, D. M. Introduction: the boundaryless career as a new employment principle. In: ARTHUR, M. B.; ROUSSEAU, D. M. The Boundaryless career: a new employment principle for a new organizational era. New York: Oxford, University Press, 1996, p. 91-114.

BECKER, G. S. Human Capital: a theoretical and empirical analysis, with special reference to education. Chicago: The University of Chicago Press, 1993.

BIANCO, N.R.D. O futuro do radio no cenário da convergência frente às incertezas quanto aos modelos de transmissão digital. Revista de Economía Política de Las Tecnologias de La Comunicación e Información, [S.1.], v. XII, n. 1, jan. - abr. 2010. Disponível em: <http://repositorio.unb.br/bitstream/10482/12282/1/ARTIGO FuturoRadioCenario.pdf $>$ Acesso em: 01 set. 2014.

BRIGGS, A. BURKE, P. A social history of the media. From Gutenberg to the internet. 2a. ed. Cambridge: Polity Press, 2005.

CARDARELLI, Renata. Mais de mil jornalistas foram demitidos nos últimos doze meses Portal Comunique-se, $28 \mathrm{dez}$ 2012. Disponível em: $<$ http://tinyurl.com/nzy9hmg> Acesso em: 21 jul. 2014. 
DANTAS, Tiago. Haddad veta projeto que transforma banca em minimercado. $O$ Estado de $S$. Paulo, 09 mai. 2013. Disponível em: < http://tinyurl.com/nnxoma4> Acesso em: 21 jul. 2014.

DUTRA, Joel S. Administração de Carreiras: uma proposta para repensar a gestão de pessoas. São Paulo: Atlas, 1996.

(Org.). Gestão de Carreiras na Empresa Contemporânea. São Paulo: Atlas, 2010.

CREATIVE destruction - A cost crisis, changing labour markets and new technology will turn an old institution on it's head. The Economist, [S.1.], 28 Jun. 2014. Disponível em: <http:// tinyurl.com/njy4dxm>. Acesso em: 21 jul. 2014.

FIGARO, Roseli . O mundo do trabalho e as organizações: abordagens discursivas de diferentes significados. ANIMUS, Revista Interamericana de Comunicaçnao Midiática, [S.1.], v.12 n.24 2013

FIGARO, Roseli ; GROHMANN, Rafael . O jornalista como receptor-trabalhador: confronto da atividade real de comunicação e trabalho. Estudos de Jornalismo e Mídia, v. 10, p. 25-20, 2013.

FILHO, João Freire. Sonhos de grandeza: o gerenciamento da vida em busca da alta performance. In FILHO, João Freire; COELHO, Maria das Graças P. A promoção do capital humano: midia, subjetividade e o espírito do capitalismo. Porto Alegre: Editora Sulina, 2011, p. $27-50$

FUVEST divulga nota de corte do vestibular 2014. O Estado de S. Paulo. 09 dez. 2013. Disponível em: <http://tinyurl.com/pxkazje> . Acesso em: 21 jul. 2014.

GREENHALGH, L. 'Nossa preocupação é com o bom jornalismo', diz publisher do 'New York Times' O Estado de S. Paulo, 17 out. 2012. Disponível em: $<$ http://politica.estadao.com. br/noticias/eleicoes, nossa-preocupacao-e-com-o-bom-jornalismo-diz-publisher-do-new-yorktimes-imp-,946575>. Acesso em: 21 jul. 2014.

GUARESCHI, Pedrinho. Mídia e democracia: o quarto versus o quinto poder. Revista Debates, Porto Alegre, v.1, n.1, p. 6-25, jul.-dez. 2007.

HALL, D. T. Career in Organizations. Pacific Palisades, CA: Goodyear, 1976.

HALL, D. T. Protean careers of the 21st century. Academy of Management Executive, [S.1.], v. 10, n 4, p.8, 1996.

Careers in and out of organizations. London: Sage, p.44, 2002.

HEIJDEN, K. V. D. Planejamento de Cenários: A arte da conversação estratégica, Bookman, Porto Alegre, 2009.

JACKSON, J. Crise dos jornais impressos chega aos países emergentes. Observatório da Imprensa, 19 fev. 2013. Disponível em: <http://tinyurl.com/lxz6nlh> Acesso em: 21 jul. 2014.

JENKINS, Henry. Cultura da convergência. São Paulo: Aleph, 2008. 
LARA, Alexandre. Em nome do público, mas sem o público: uma análise do sistema de fonte aberta no jornalismo do século XXI. s/d. Disponível em: $<\underline{\text { http://www.bocc.ubi.pt/pag/lara-al- }}$ exandre-em-nome-do-publico.pdf $>$ Acesso em: 21 jul. 2014.

LIMA, Cláudia do Carmo Nonato. Comunicação e Trabalho do Jornalista: o perfil dos jornalistas de São Paulo a partir da reconfiguração dos processos produtivos da informação. São Paulo, 2010, 313 fl. Dissertação (Mestrado). Escola de Comunicações e Artes, Universidade de São Paulo, São Paulo, 2010.

LINS DA SILVA, C. E. Como atrair os jovens para o jornal. Folha de S. Paulo, 18 jan. 2009.

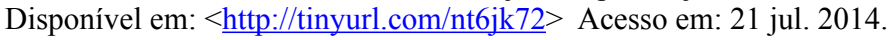

LONDON, M.; STUMPH, S. Managing careers. Massachusetts: Addison-Wesley, 1982.

MEIO E MENSAGEM. Circulação de jornais cai 1,9\% em 2013. Meio e Mensagem. 27 jan. 2014. Disponível em: <http://tinyurl.com/ljvbnzf $>$ Acesso em: 21 jul. 2014.

MICK, Jacques; LIMA, Samuel. Perfil do Jornalista Brasileiro - caraterísticas demográficas, políticas e do trabalho jornalístico em 2012. Florianópolis: Insular, 2013.

NEUBERGER, R. S. A. O Rádio na Era da Convergência das Mídias, Cruz das Almas, BA: UFRB, 2012.

NEVES, M. Decisões de Carreira: Um Estudo de Caso com Engenheiros Civis no Segmento de Incorporação e Construção, São Paulo, 2012, fl.42 Dissertação (Mestrado) em Administração. Pontifícia Universidade Católica de São Paulo, São Paulo, 2012.

PINCHOT, G. Intrapreuneuring: por que você não precisa deixar a empresa para tornar-se um empreendedor. São Paulo: Habra, 1989.

McQUAIL, Denis. Teoria da comunicação de massas. Lisboa: Fundação Calouste Gulbenkian, 2003 .

SENNETT, Richard. A cultura do novo capitalismo. Rio de Janeiro: Record, 2006.

SCHEIN, E. H. Career dynamics: matching individual and organizational needs. Massachusetts: Addison-Wesley, 1978.

. Career Anchors Revisited: Implications for career development in the 21st century. Academy of Management Executive,[S.1.], v, 10, n. 4, nov. 1996.

SUPREMO TRIBUNAL FEDERAL. Supremo decide que é inconstitucional a exigência de diploma para o exercício do jornalismo. Notícias STF. Disponível em: $<\underline{\text { http://tinyurl.com/ }}$ $\underline{\text { m8sqwm> }} .21$ jul. 2014.

TREVISAN, Wilson; AMORIM, Maria Cristina Sanches; MORGADO, Flávio. Empreendedorismo: do herói Schumpteriano ao Executivo de Sucesso. Revista Pensamento e Realidade, [S.1.] Ano IX - v.26, n.1/2011

VAN MAANER, J. (Ed.). Organizational careers: some new perspectives. New York,: John Wiley, 1977. 
VELOSO, E.F.R. Carreiras sem fronteiras e transição profissional no Brasil. São Paulo: Atlas, 2012.

VELOSO, E.F.R.; DUTRA, J.S. Evolução do Conceito de Carreira e sua Aplicação para a Organização e para as Pessoas. In: DUTRA, Joel S. Gestão de Carreiras na Empresa Contemporânea, São Paulo, Atlas, 2010., p.. 3-39

Submissão: 19/08/2014

Felipe Arruda Mortara é Mestrando em Administração - Pontifícia Universidade Católica de São Paulo (PUC-SP), e bolsista da Coordenação de Aperfeiçoamento de Pessoal de Nível Superior (CAPES), estuda Gestão de Carreiras, com foco nas carreiras jornalíticas. Possui graduação em Jornalismo pela Faculdade Cásper Líbero (2007). Endereço para correspondência: Rua Francisco Cruz 317, Vila Mariana, CEP: 04117- 090. São Paulo/SP. E-mail: felipemortara@gmail.com.

Leonardo Nelmi Trevisan é Professor Doutor do Programa de Estudos Pós-Graduados em Administração - Pontifícia Universidade Católica de São Paulo (PUC-SP) e Professor de Jornalismo na ESPM-SP. É graduado em História (1976), mestre em História Econômica (1984) e doutor em Ciência Política (1993), todos pela Universidade de São Paulo. Pós-doutor em Economia do Trabalho, pela University of London (1997) e Warwick University (1998).

E-mail: 1ntrevisan@pucsp.br 